CLINICAL STUDY

\title{
Epidemiological survey on the relationship between different iodine intakes and the prevalence of hyperthyroidism
}

Fan Yang, Weiping Teng, Zhongyan Shan, Haixia Guan, Yushu Li, Ying Jin, Fengnan Hu, Xiaoguang Shi, Yajie Tong, Wei Chen, Bai Yuan, Zhanyi Wang ${ }^{1}$, Bingyuan Cui ${ }^{2}$ and Shiming Yang ${ }^{2}$

Department of Endocrinology, The First Affiliated Hospital of China Medical University, Shenyang, China, ${ }^{1}$ Liaoning Provincial Office for Control and Prevention of Endemic Disease, Shenyang, China and ${ }^{2}$ Hebei Provincial Institute for Control and Prevention of Endemic Disease, Shijiazhuang, China

(Correspondence should be addressed to Weiping Teng, China Medical University, 92 North 2nd Road, Heping District, Shenyang 110001, China;

Email: tengweiping@hotmail.com)

\begin{abstract}
Objective: To investigate the effect of different levels of iodine intake on the prevalence of hyperthyroidism and the impact of universal salt iodization on the incidence of hyperthyroidism.

Design: A comparative cross-sectional and longitudinal survey was conducted in three areas with borderline iodine deficiency, mild iodine excess (previously mild iodine deficiency) and severe iodine excess. Universal salt iodization had been introduced 3 years previously except in the area with borderline iodine deficiency.

Methods: In total 16287 inhabitants from three areas answered a questionnaire concerning the history of thyroid disease. Among them 3761 unselected subjects received further investigations including thyroid function, thyroid autoantibodies, thyroid ultrasonography and urinary iodine excretion. Results: Among areas with median urinary iodine excretion of $103 \mu \mathrm{g} / \mathrm{l}, 375 \mu \mathrm{g} / \mathrm{l}$ and $615 \mu \mathrm{g} / \mathrm{l}(P<$ $0.05)$, the prevalence of hyperthyroidism did not differ significantly $(1.6 \%, 2 \%$ and $1.2 \%)$. The prevalence of subclinical hyperthyroidism was higher in areas with borderline iodine deficiency and mild iodine excess than in the area with severe excess iodine intake $(3.7 \%, 3.9 \%$ and $1.1 \%$, $P<0.001)$. The prevalence of Graves' disease and its proportion in hyperthyroidism did not differ among areas. The incidence of hyperthyroidism did not significantly increase after the introduction of universal salt iodization.

Conclusion: Different iodine intakes under a certain range do not affect the prevalence and type of hyperthyroidism. Subclinical hyperthyroidism is more prevalent in the iodine deficient area than in the severe iodine excessive area. In the area with mild iodine deficiency, the introduction of universal salt iodization may not be accompanied by an increased incidence of hyperthyroidism.
\end{abstract}

European Journal of Endocrinology 146 613-618

\section{Introduction}

Iodine deficiency is a worldwide health problem and is a leading cause of mental retardation in childhood, cretinism and endemic goiter. These are the main manifestations of iodine deficiency disorders (IDD) (1). The recommendation of the World Health Organization (WHO), the United Nations Children's Fund (UNICEF) and the International Council for Control of Iodine Deficiency Disorders (ICCIDD), is that adequate iodine intake be between 100 and $199 \mu \mathrm{g} / \mathrm{l}$ based on median urinary iodine excretion in school-aged children (2). Universal salt iodization (USI) has been agreed to be an effective means of eliminating iodine deficiency (3). However, after the increment in iodine intake, an increased incidence of hyperthyroidism due to the occurrence of iodine-induced hyperthyroidism (IIH) was observed in many previously iodine-deficient areas (4-6). To investigate the effect of different iodine intakes on the prevalence of hyperthyroidism and the impact of USI on the incidence of hyperthyroidism, we performed a comparative cross-sectional and longitudinal survey in areas with borderline iodine deficiency, mild iodine excess, and severe iodine excess. Our study is characterized as a large-scale and population-based study with unified research methods and diagnostic criteria. Thus, we could avoid the bias in analyzing the difference in the prevalence and types of hyperthyroidism attributed to the different iodine intakes.

\section{Subjects and methods \\ Research areas and subjects}

Panshan, Zhangwu and Huanghua were chosen as the research areas as, according to the records of local endemic institutes, the historical status of iodine 
nutrition was borderline iodine deficiency, mild iodine deficiency and long-term iodine excess respectively. Panshan was a longstanding iodine-deficient area because the inhabitants took self-made salt with a low iodine content. At the end of 1995, the median urinary iodine excretion (MUI) of school-aged children was $86 \mu \mathrm{g} / \mathrm{l}$. Zhangwu was a mild iodine-deficient area before 1996. Huanghua has been an area with iodine excess for over 20 years because of the high iodine content in the water. USI has been introduced in Zhangwu and Huanghua since 1996.

All the inhabitants living in the research areas, 4343 from Panshan, 7714 from Zhangwu and 4230 from Huanghua answered a questionnaire concerning the history and medication of thyroid disease. Among them 1103, 1584 and 1074 unselected subjects from the three areas received further examinations. Demographic characteristics of both the questioned inhabitants and the examined subjects did not differ significantly among areas (Table 1). All subjects were older than 14 years and had lived in the areas of interest for over 10 years.

\section{Thyroid function and autoantibodies tests}

Blood samples were obtained from all subjects during the time interval $0800-1200 \mathrm{~h}$. Sera were separated and stored at $-20^{\circ} \mathrm{C}$ until analyses. Serum thyrotropin (TSH), thyroid peroxidase antibody (TPOAb), and thyroglobulin antibody (TGAb) were measured by an immunochemiluminescent assay (IMMULITE, DPC, Los Angeles, CA, USA) in all examined subjects. The detection limit of the TSH assay was $0.002 \mathrm{mU} / \mathrm{l}$. The intra-assay coefficient of variation (CV) was 1.95$6.66 \%$; the interassay $\mathrm{CV}$ was $4.18 \%$. The reference range for serum TSH was $0.3-4.8 \mathrm{mU} / \mathrm{l}$ corresponding to the 2.5th and 97.5th percentiles in 2503 normal subjects (no previous thyroid disease, no goiter and nodules at ultrasound, TPOAb negative (below $35 \mathrm{IU} / \mathrm{l}$ ) and TGAb negative (below $40 \mathrm{IU} / \mathrm{l})$ ). For subjects with TSH values outside the reference range, serum free thyroxine $\left(\mathrm{FT}_{4}\right)$ and serum free tri-iodothyronine $\left(\mathrm{FT}_{3}\right)$ concentrations were tested (IMMULITE,

Table 1 Characteristics of inhabitants and subjects in Panshan, Zhangwu and Huanghua.

\begin{tabular}{lccc}
\hline Characteristics & Panshan & Zhangwu & Huanghua \\
\hline Questioned inhabitants $(n)$ & 4343 & 7714 & 4230 \\
Gender ratio (male/female) & 1.05 & 1.07 & 0.98 \\
Mean age (years) & 39.98 & 39.95 & 37.96 \\
Range of age (years) & $14-101$ & $14-96$ & $14-91$ \\
Examined subjects $(n)$ & 1103 & 1584 & 1074 \\
Gender ratio (male/female) & 0.35 & 0.31 & 0.34 \\
Mean age (years) & 36.18 & 39.78 & 36.97 \\
Range of age (years) & $14-88$ & $14-95$ & $14-79$ \\
\hline
\end{tabular}

DPC). The reference ranges of $\mathrm{FT}_{4}$ and $\mathrm{FT}_{3}$ were 10.3$24.5 \mathrm{pmol} / \mathrm{l}$ and $2.3-6.3 \mathrm{pmol} / \mathrm{l}$ according to the standards provided by the manufacturer. The intra-assay and interassay coefficients of variation were $4.65 \%$ and $5.16 \%$ for $\mathrm{FT}_{4}$, and $5.89 \%$ and $7.28 \%$ for $\mathrm{FT}_{3}$. For those with a TSH value below $0.3 \mathrm{mU} / \mathrm{l}$, serum thyrotropin receptor antibody (TRAb) concentrations were measured $\left({ }^{125} \mathrm{I}\right.$ RRA Kit, Diasorin, Stillwater, $\mathrm{MN}$, USA), and the reference range of serum TRAb was $<2 \mathrm{U} / \mathrm{l}$ (taking the 95th percentile of values from 156 normal participants as the upper limit).

\section{Urinary iodine excretion}

Fasting urine samples were collected from all subjects and measured for iodine excretion by the method based on the Sandell-Kolthoff reaction (7). The interassay and intra-assay coefficients of variation were $2.1 \%$ and $3.1 \%$ respectively. The detection limit was $5 \mu \mathrm{g} / \mathrm{l}$ and the recovery rate was more than $95 \%$. Urinary iodine excretion in schoolchildren was also measured.

\section{Thyroid ultrasound}

Thyroid ultrasound examination was performed in subjects by a portable instrument (SA600, Medison, Seoul, Korea) with a $7.5 \mathrm{MHz}$ linear transducer. Thyroid volume was calculated with the formula: width $\times$ length $\times$ thickness $\times 0.479$ for each lobe $(8)$. Goiter was diagnosed in adults if the thyroid volume was over $25.6 \mathrm{ml}$ (mean +2 s.D.) in males and $19.4 \mathrm{ml}$ $($ mean +2 s.D. $)$ in females.

\section{Diagnostic criteria}

Overt hyperthyroidism was diagnosed if serum TSH $<0.3 \mathrm{mU} / \mathrm{l}$ and $\mathrm{FT}_{4}>24.5 \mathrm{pmol} / \mathrm{l}$ or $\mathrm{FT}_{3}$ $>6.3 \mathrm{pmol} / \mathrm{l}$. Subclinical hyperthyroidism was diagnosed if serum TSH $<0.3 \mathrm{mU} / \mathrm{l}$ with normal $\mathrm{FT}_{4}$ and $\mathrm{FT}_{3}$. Graves' disease was diagnosed if (i) there was overt hyperthyroidism, (ii) TRAb $>2$ IU/l or TPOAb $>100 \mathrm{IU} / \mathrm{l}$, and (iii) there was a diffuse goiter or normal thyroid under ultrasonography. Toxic nodular goiter was diagnosed if (i) there was overt hyperthyroidism, (ii) nodular goiter was seen under ultrasonography, (iii) TRAb $<2 \mathrm{U} / \mathrm{l}$ and TPOAb $<100$ IU/l.

\section{Statistics}

Data processing was performed with SAS software version 6.12. Non-parametric statistics were used to analyze urinary iodine excretion (Kruskal-Wallis). Comparison between frequencies was performed by Chi-square analysis. The level of significance was set to $5 \%$. 


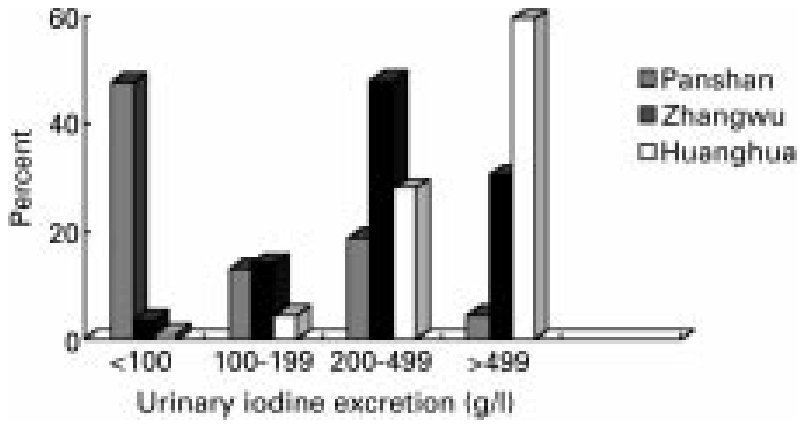

Figure 1 Distribution (as a percentage) of different levels of urinary iodine excretion in the subjects in Panshan, Zhangwu and Huanghua. Median urinary iodine excretion in Panshan, Zhangwu and Huanghua was $103 \mu \mathrm{g} / \mathrm{l}, 375 \mu \mathrm{g} / \mathrm{l}$ and $615 \mu \mathrm{g} / \mathrm{l}$ respectively $(P<0.05)$

\section{Results}

\section{Status of iodine nutrition}

The MUI of subjects in Panshan, Zhangwu and Huanghua were $103 \mu \mathrm{g} / \mathrm{l}, 375 \mu \mathrm{g} / \mathrm{l}$ and $615 \mu \mathrm{g} / \mathrm{l}$ respectively $(P<0.05)$, which indicated borderline iodine deficiency, mild iodine excess and severe iodine excess in the three areas (Fig. 1). In school-aged children, the MUI was $84 \mu \mathrm{g} / \mathrm{l}$ in Panshan, $243 \mu \mathrm{g} / \mathrm{l}$ in Zhangwu and $651 \mu \mathrm{g} / \mathrm{l}$ in Huanghua. No subjects were found taking drugs containing iodine during the period of the investigation. The iodine content of the self-made salt in Panshan was $<3.4 \mathrm{mg} / \mathrm{kg}$, and the average iodine concentration of iodized salt was $54 \mathrm{mg} / \mathrm{kg}$ in Zhangwu and $23 \mathrm{mg} / \mathrm{kg}$ in Huanghua. In Huanghua, the iodine concentration of water was remarkably high $(174.7-260.5 \mu \mathrm{g} / \mathrm{l})$.

\section{Prevalence of hyperthyroidism and subclinical hyperthyroidism}

The prevalence of previously diagnosed hyperthyroidism acquired from the questionnaires did not differ significantly among areas $(0.87 \%$ in Panshan, $0.42 \%$ in Zhangwu and $0.62 \%$ in Huanghua). The prevalence of hyperthyroidism, subclinical hyperthyroidism and Graves' disease is shown in Table 2. No significant differences in the prevalence of hyperthyroidism and
Graves' disease were found among areas. Compared with Huanghua, the prevalence of subclinical hyperthyroidism detected by biochemical screening was significantly higher in Panshan and Zhangwu but did not differ significantly from each other.

\section{Types of hyperthyroidism and features of subclinical hyperthyroidism}

Graves' disease was the main type of hyperthyroidism and its proportion of the cases with hyperthyroidism was similar among the areas (Fig. 2). The prevalence of thyroid autoantibody (TAA) in subjects with hyperthyroidism did not differ between areas, but it was significantly higher in subjects with subclinical hyperthyroidism in Huanghua compared with those in Panshan and Zhangwu (Table 3). No subjects took thyroid hormone. No pregnant women or patients with severe illness participated in the survey.

\section{Prevalence of goiter}

Goiter was found in $29 \%, 8.4 \%$ and $8.9 \%$ of schoolaged children in Panshan, Zhangwu and Huanghua respectively $(P<0.001)$. The prevalence of diffuse goiter in subjects without known thyroid disease differed significantly between areas $(18.2 \%$ in Panshan, $12.6 \%$ in Zhangwu and $4.2 \%$ in Huanghua, $P<0.001)$. For nodular goiter, no significant differences were found $(3.4 \%, 3.3 \%$ and $2.5 \%$ respectively). Goiter was more prevalent in subjects with subclinical hyperthyroidism but without known thyroid disease than in subjects with normal TSH and without known thyroid disease in current and previous iodine-deficient areas $36.6 \%$ vs $19.6 \%$ in Panshan, $P=0.009 ; \quad 31.1 \%$ vs $15.7 \%$ in Zhangwu, $P<$ 0.001). However, in Huanghua with severe iodine excess, no significant difference was found $(8.3 \%$ vs $4.5 \%)$.

\section{Variation in the incidence of hyperthyroidism after USI}

In Zhangwu and Huanghua, iodized salt was available at the beginning of 1996. The number of patients with

Table 2 The prevalence of hyperthyroidism, subclinical hyperthyroidism, Graves' disease in examined subjects of Panshan, Zhangwu and Huanghua.

\begin{tabular}{|c|c|c|c|c|c|c|}
\hline \multirow[b]{2}{*}{ Group } & \multicolumn{2}{|c|}{$\begin{array}{l}\text { Panshan } \\
(n=1103)\end{array}$} & \multicolumn{2}{|c|}{$\begin{array}{l}\text { Zhangwu } \\
(n=1584)\end{array}$} & \multicolumn{2}{|c|}{$\begin{array}{l}\text { Huanghua } \\
(n=1074)\end{array}$} \\
\hline & $n$ & $\%$ & $n$ & $\%$ & $n$ & $\%$ \\
\hline Overt hyperthyroidism & 18 & 1.6 & 32 & 2 & 13 & 1.2 \\
\hline Subclinical hyperthyroidism & 41 & $3.7^{*}$ & 62 & $3.9^{*}$ & 12 & 1.1 \\
\hline Graves' disease & 15 & 1.36 & 20 & 1.26 & 12 & 1.1 \\
\hline
\end{tabular}




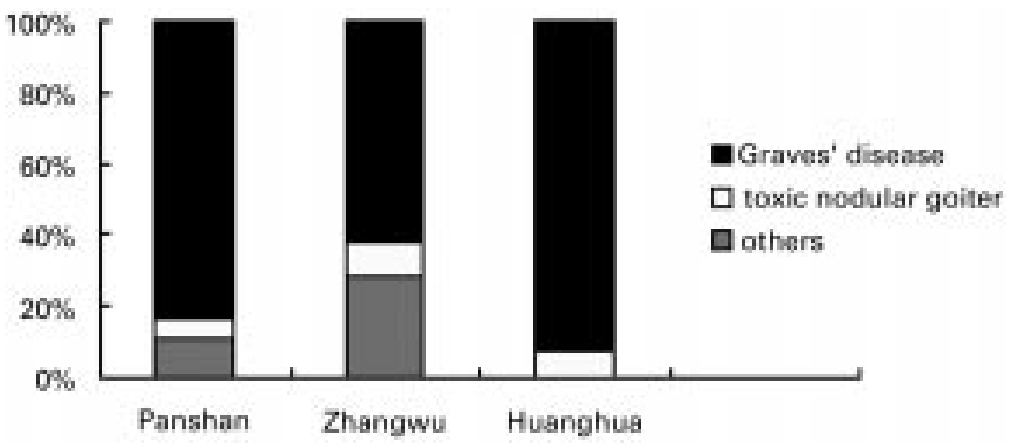

Figure 2 The proportion of different causes of hyperthyroidism in Panshan, Zhangwu and Huanghua with borderline iodine deficiency, mild iodine excess and severe iodine excess respectively. No significant difference between areas was found in the proportion of Graves' disease in the subjects with hyperthyroidism.

Table 3 The prevalence of thyroid autoantibodies in overt hyperthyroidism and subclinical hyperthyroidism.

\begin{tabular}{|c|c|c|c|c|c|c|}
\hline \multirow[b]{2}{*}{ Group } & \multicolumn{2}{|c|}{ Panshan } & \multicolumn{2}{|c|}{ Zhangwu } & \multicolumn{2}{|c|}{ Huanghua } \\
\hline & $n$ & $\%$ & $n$ & $\%$ & $n$ & $\%$ \\
\hline Overt hyperthyroidism & \multicolumn{2}{|c|}{$n=18$} & \multicolumn{2}{|c|}{$n=32$} & \multicolumn{2}{|c|}{$n=13$} \\
\hline TPOAb & 11 & 61.1 & 16 & 50 & 10 & 76.9 \\
\hline TGAb & 6 & 33.3 & 10 & 31.3 & 6 & 46.2 \\
\hline TRAb & 10 & 55.6 & 10 & 31.3 & 7 & 53.8 \\
\hline Subclinical hyperthyroidism & \multicolumn{2}{|c|}{$n=41$} & \multicolumn{2}{|c|}{$n=62$} & \multicolumn{2}{|c|}{$n=12$} \\
\hline TPOAB & 8 & $19.5^{*}$ & 9 & $14.5^{\star}$ & 6 & 50 \\
\hline TRAb & 5 & $12.2^{\star *}$ & 4 & $6.5^{\star \star}$ & 9 & 75 \\
\hline Any kind of autoantibody & 16 & $39^{\star \star}$ & 15 & $24.2^{\star *}$ & 11 & 91.7 \\
\hline
\end{tabular}

${ }^{\star} P<0.05$ vs Huanghua, ${ }^{\star \star} P<0.001$ vs Huanghua.

diagnosed hyperthyroidism was collected in the period between 1991 and 1999 in the three areas in order to calculate the average incidence of hyperthyroidism in 1991-1995 (before USI) and in 1996-1999 (after USI). The incidence of hyperthyroidism increased significantly in Panshan (80.6/100000 vs 27.6/ $100000, P<0.05$ ), and insignificantly in Zhangwu $(35.6 / 100000$ vs 23.4/100000) and in Huanghua $(37 / 100000$ vs $35 / 100000)$ after the introduction of USI (Fig. 3).

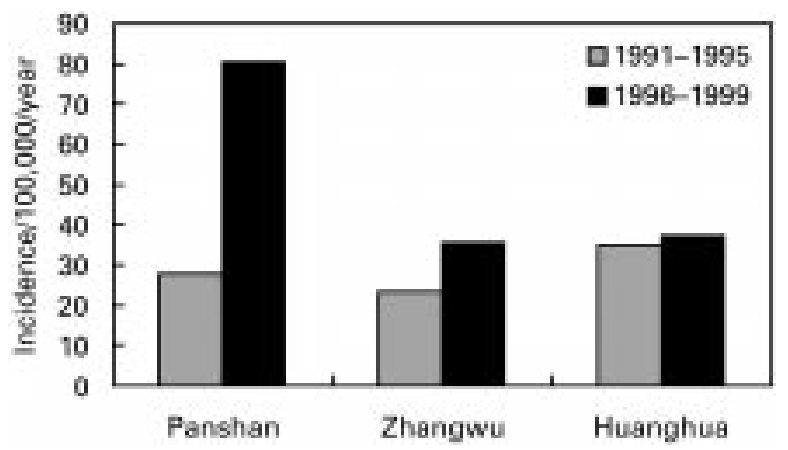

Figure 3 Comparison of the average incidence of diagnosed hyperthyroidism in 1991-1995 (before USI) and in 1996-1999 (after USI). A significant increase was found in Panshan $(P<0.05)$

\section{Discussion}

To investigate the effect of different iodine intakes on the prevalence of hyperthyroidism and the impact of universal salt iodization on the incidence of hyperthyroidism, we performed a comparative cross-sectional and longitudinal survey in three areas with median urinary iodine excretion of $103 \mu \mathrm{g} / \mathrm{l}, 375 \mu \mathrm{g} / \mathrm{l}$ and $615 \mu \mathrm{g} / \mathrm{l}$. The survey was conducted in the general population and the three areas were comparable in terms of demographic and health characteristics except for the significant difference in urinary iodine excretion.

The prevalence of hyperthyroidism did not differ significantly between the three areas with remarkably different urinary iodine excretion. It has been demonstrated in a survey from Denmark that the incidence of hyperthyroidism is markedly higher in an iodinedeficient area (urinary iodine excretion between 40$70 \mu \mathrm{g} / \mathrm{l}$ ) than in an iodine-excessive area (urinary iodine excretion around $300 \mu \mathrm{g} / \mathrm{l}$ ) due to the higher incidence and proportion of toxic nodular goiter in the iodine-deficient area (9). In our study, the degree of iodine deficiency in Panshan was only at the borderline level. Compared with the figures of a survey from Italy, the frequency of nodular goiter was remarkably low (10). Therefore, as a secondary cause of hyperthyroidism, non-autoimmune factors did not significantly change the prevalence of hyperthyroidism in Panshan. 
We found that USI did not affect the incidence of hyperthyroidism in areas with mild iodine deficiency. It is well established that iodine supplementation to an iodine-deficient population may be accompanied by an increase in the incidence of hyperthyroidism $(4-6)$. The main cause is due to the occurrence of IIH elicited by uncontrolled hormone synthesis in thyroid autonomous tissues developed during the period of low iodine intake. The increase is associated with a rapid correction due to the recent excessive increment in iodine intake $(<2$ years) and the duration as well as the severity of the previous iodine deficiency (11, 12). The discrepancy in our survey may relate to the fact that Zhangwu was previously a mildly iodinedeficient area. The prevalence of nodular goiter in Zhangwu was similar to that in Panshan but was lower than that from areas with moderate iodine deficiency (10). It has also been demonstrated that the decrease in goiter takes time to be achieved after the increment in iodine intake $(13,14)$. Thus, we inferred that the important cause of thyroid autonomy, i.e. nodular goiter as the main biological basis of IIH was relatively rare in this area before USI. In addition, the significant increased incidence of hyperthyroidism found in Panshan with borderline iodine deficiency but without the influence of USI, suggested that the increment in iodine intake is not the only cause leading to an increase of hyperthyroidism $(15,16)$.

Graves' disease is the main cause of hyperthyroidism in the general population and its frequency is not associated with iodine intake when the urinary iodine excretion in the population reaches the borderline of adequate level. Our results parallel the findings from Denmark that Graves' disease was the dominant type of hyperthyroidism in the area with excessive iodine intake (9). However, the similar prevalence of Graves' disease independent of the iodine intake was not in agreement with the findings from Austria (6). Other findings in our study demonstrated that the higher prevalence of hypothyroidism due to autoimmune thyroiditis (Hashimoto disease and atrophy thyroiditis) was closely related with the increase in iodine intake although no difference was found in the prevalence of thyroid autoantibodies in the general population among the three areas (17).

Subclinical hyperthyroidism was more prevalent and was partly related to thyroid autonomy in the areas with current and previous iodine deficiency. It is established that thyroid autonomy due to long-term iodine deficiency may lead to hyperfunction, which was one of the causes of subclinical hyperthyroidism $(18,19)$. The autonomous tissues may appear as multiple areas either encapsulated or diffuse (18). In Panshan and Zhangwu, the frequency of goiter in subjects with subclinical hyperthyroidism was significantly higher than that in subjects with normal TSH. Our findings are in agreement with the findings that thyroid enlargement and macronodular thyroid structure were found to be more prevalent in subjects with suppressed TSH than in subjects with normal TSH in the areas with mild and moderate iodine deficiency (20).

On the other hand, the frequency of goiter in subjects with subclinical hyperthyroidism was similar between subjects with subclinical hyperthyroidism and subjects with normal TSH. But the significantly higher prevalence of TAA in subjects with subclinical hyperthyroidism in Huanghua suggests that subclinical hyperthyroidism may relate to thyroid autoimmunity in an area with severe iodine excess. This is in accordance with the results of a study from Japan with recognized excessive iodine intake (21).

In conclusion, different iodine intakes under a certain range (MUI 100-600 $\mu \mathrm{g} / \mathrm{l}$ ) do not affect the prevalence and type of hyperthyroidism. Subclinical hyperthyroidism was more prevalent and was related to thyroid autonomy in the areas with current and previous iodine deficiency. In the area with mild iodine deficiency, the introduction of universal salt iodization may not be accompanied with an increase in the incidence of hyperthyroidism.

\section{Acknowledgements}

This study was supported by grants from the China Medical Board and the National Natural Science Fund of China.

\section{References}

$1 \mathrm{WHO} / \mathrm{UNICEF} / \mathrm{ICCIDD}$. Indicators for assessing iodine deficiency disorders and their control programs through salt iodization. Geneva: WHO, 1994.

$2 \mathrm{WHO} / \mathrm{UNICEF} / \mathrm{ICCIDD}$. Assessment of the iodine deficiency disorders and monitoring their elimination. Geneva: WHO, 2001.

3 WHO. Iodine and health. Geneva: WHO, 1994.

4 Todd CH, Allain T, Gomo ZA, Hasler JA, Ndiweni M \& Oken E. Increase in thyrotoxicosis associated with iodine supplements in Zimbabwe. Lancet $19953461563-1564$.

5 Bourdeaux PP, Ermans AM, Mukalay WA, Mukalay A, Filetti S \& Vignery R. Iodine induced thyrotoxicosis in Kiwu, Zaire. Lancet $1996347552-553$.

6 Mostbeck A, Galvan G, Bauer P, Eber O, Atefie K, Dam K et al. The incidence of hyperthyroidism in Austria from 1987-1995 before and after an increase in salt iodization in 1990. European Journal of Nuclear Medicine 199825 367-374.

7 Dunn JT, Crutchfield HE, Gutekunst R \& Dunn AD. Two simple methods for measuring iodine in urine. Thyroid 19933 119-123.

8 Brunn J, Block U, Ruf G, Bos I, Kunze WP \& Scriba PC. Volumetrie der schilddruesenlappen mittels real-time-sonographie. Deutsche Medizinische Wochenschrift 1981106 1338-1340.

9 Lauberg P, Pedersen KM, Vestergaard H \& Sigurdsson G. High incidence of multinodular toxic goitre in the elderly population in a low iodine intake area vs high incidence of Graves' disease in the young in a high iodine intake area: comparative surveys of thyrotoxicosis epidemiology in East-Jutland Denmark and Iceland. Journal of Internal Medicine 1991229 415-420.

10 Delange F, de Benoist B \& Alnwick D. Risks of iodine-induced hyperthyroidism after correction of iodine deficiency by iodized salt. Thyroid $19999545-556$. 
11 Stanbury JB, Ermans AE, Bourdoux P, Todd C, Oken E, Tonglet R et al. Iodine-induced hyperthyroidism: occurrence and epidemiology. Thyroid $1998 \mathbf{8} 83-100$.

12 Aghini-Lombardi F, Antonangeli L, Martino E, Vitti P, Maccherin $\mathrm{D}$, Leoli $\mathrm{F}$ et al. The spectrum of thyroid disorders in an iodinedeficient community: the Pescopagano survey. Journal of Clinical Endocrinology and Metabolism 199984 561-566.

13 Kusi Z, Lechpammer S, Lukinac L, Petrovi I \& Noethig-Hus D. First beneficial results of the implementation of Croatian new law on salt iodination. Journal of Endocrinological Investigation 199922 $747-751$.

14 Lindberg O, Andersson LC \& Lamberg BA. The impact of 25 years of iodine prophylaxis on the adult thyroid weight in Finland. Journal of Endocrinological Investigation 198912 789-793.

15 Berglund J. Ericsson UB \& Hallengren B. Increased incidence of thyrotoxicosis in Malmou during the years 1988-1990 as compared to the years 1970-1974. Journal of Internal Medicine $199623957-62$.

16 Michelangeli VP, Pawape G, Sinha A, Ongugu K, Linge D, Sengupta SH et al. Clinical features and pathogenesis of thyrotoxicosis in adult Melanesians in Papua New Guinea. Clinical Endocrinology 200052 261-266.
17 Li Y \& Teng W. A comparative screening for autoimmune thyroid disease in areas with different iodine intake. Hong Kong Medical Journal 20017 (Suppl 2) 058.

18 Corvilain B, Van Sande J, Dumont JE, Bourdoux P \& Ermans AM. Autonomy in endemic goiter. Thyroid 19988 107-113.

19 Marqusee E, Haden ST \& Utiger RD. Subclinical thyrotoxicosis. Endocrinology and Metabolism Clinics of North America 199827 37-49.

20 Knudsen N, Bulow I, Jorgensen T, Laurberg P, Ovesen L \& Perrild H. Comparative study of thyroid function and types of thyroid dysfunction in two areas in Denmark with slightly different iodine status. European Journal of Endocrinology 2000143 485-491.

21 Kasagi K, Takeuchi R, Misaki T, Kousaka T, Miyamoto S, Iida Y et al. Subclinical Graves' disease as a cause of subnormal TSH levels in euthyroid subjects. Journal of Endocrinological Investigation $199720183-188$.

Received 26 October 2001

Accepted 1 February 2002 